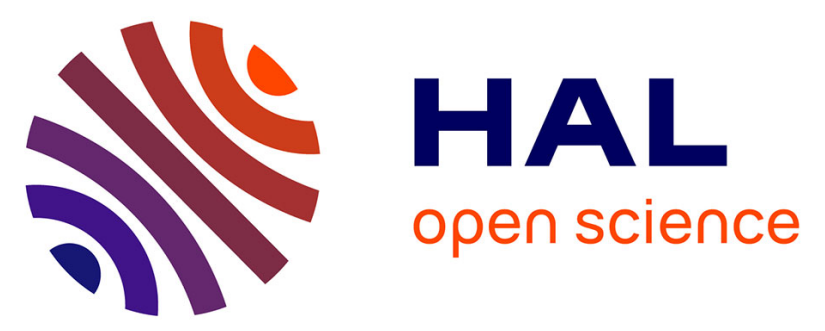

\title{
Quantitative structural characterization of polymer-clay nanocomposites and discussion of an "ideal" microstructure, leading to the highest mechanical reinforcement
}

Karine Masenelli-Varlot, Gérard Vigier, Alexandre Vermogen, Catherine Gauthier, Jean-Yves Cavaille

\section{To cite this version:}

Karine Masenelli-Varlot, Gérard Vigier, Alexandre Vermogen, Catherine Gauthier, Jean-Yves Cavaille. Quantitative structural characterization of polymer-clay nanocomposites and discussion of an "ideal" microstructure, leading to the highest mechanical reinforcement. Journal of Polymer Science Part B: Polymer Physics, 2007, 45 (11), pp.1243-1251. 10.1002/polb.21186 . hal-00434175

\author{
HAL Id: hal-00434175 \\ https://hal.science/hal-00434175
}

Submitted on 13 Jun 2019

HAL is a multi-disciplinary open access archive for the deposit and dissemination of scientific research documents, whether they are published or not. The documents may come from teaching and research institutions in France or abroad, or from public or private research centers.
L'archive ouverte pluridisciplinaire HAL, est destinée au dépôt et à la diffusion de documents scientifiques de niveau recherche, publiés ou non, émanant des établissements d'enseignement et de recherche français ou étrangers, des laboratoires publics ou privés. 
Quantitative structural characterization of polymer-clay nanocomposites and discussion of an "ideal" microstructure, leading to the highest mechanical reinforcement

K. Masenelli-Varlot, G. Vigier, A. Vermogen, C. Gauthier, J.Y. Cavaillé

MATEIS, INSA-Lyon, CNRS UMR 5510, F-69621 Villeurbanne, France

\begin{abstract}
Montmorillonite and other lamellar materials are very promising for reinforcing semicrystalline thermoplastics, especially if exfoliation is achieved. In order to understand the macroscopic properties of polymers filled with lamellar materials, it is unavoidable to characterize their structures. Parameters have to be determined such as the clay dispersion state, the orientations of the clay and of the polymer crystalline lamellae, and the interactions between the clay and the polymer matrix.

Beyond the over-simple description as "intercalated" or "exfoliated" structures, we propose a multi-scale characterization of the state of exfoliation of the clay platelets based on the analysis of Optical Microscopy and Transmission Electron Microscopy images. The results have been confirmed by Small Angle X-Ray Scattering, which also gives pieces of information regarding the orientation of the clay platelets and of the polymer crystalline lamellae. Lastly, we propose the use of Dynamic Mechanical Analysis (DMA) as an indirect technique to probe the filler/matrix interfacial adhesion strength. In the light of these characterizations, we discuss of a structure which is thought to lead to the highest reinforcement below and above $\mathrm{Tg}$.
\end{abstract}




\section{Introduction}

Since the discovery of polyethylene in 1934, semi-crystalline thermoplastics have gained more and more interest : they are light, recyclable, easy to process and have good impact properties. Although their mechanical characteristics are sufficient around the ambient temperature, they drop sensitively when the temperature reaches the glass transition temperature. The introduction of an inorganic filler is required to obtain a composite material with improved properties. From a general point of view, the maximum improvement of mechanical properties should be observed with inorganic nanofillers exhibiting a high aspect ratio.

One of the most studied lamellar nanofillers is montmorillonite. Each of its lamellar unit is composed of a layer of alumina octahedrons, surrounded by two layers of silica tetrahedrons. The partial substitution of $\mathrm{Al}^{+3}$ ions by $\mathrm{Mg}^{+2}$ ions creates an excess of negative charges in the layer, which is compensated by the presence of cations in the inter-layer gallery. By exchanging these cations by intercalants, the inter-gallery distance and the further compatibility of montmorillonite with the polymer can be controlled [1]. Depending on the organization of the montmorillonite platelets in the matrix, either intercalated or exfoliated structures can be obtained. In the intercalated structure, the polymer is located between the montmorillonite platelets, which are still stacked together. In the exfoliated structure, the platelets are completely dispersed in the matrix and well separated from one to another.

Montmorillonite and other lamellar materials are very promising for reinforcing semicrystalline thermoplastics. It was previously shown that polyamide/montmorillonite nanocomposites could exhibit sensitively improved mechanical properties [2], thermomechanical performance [3, 4] and barrier properties [5, 6] with montmorillonite contents lower than 5 wt.\%. Such improved properties could not be obtained with nanoscale spherical fillers, even at higher contents [7]. Moreover, relationships between the state of exfoliation, 
the structure and the mechanical reinforcement were clearly evidenced $[8,9,10]$. However, these studies do not take into account all the microstructural characteristics of the nanocomposite (crystallinity and texture of the matrix, dispersion state and orientation of the clay, etc.).

We believe that drastically improved macroscopic properties (for instance mechanical properties above the glass temperature, barrier properties, ...) can be achieved when introducing lamellar fillers into semi-crystalline thermoplastics, and probably not into amorphous polymers. Indeed, semi-crystalline thermoplastics can be seen as nanocomposites by themselves, since they are composed of an amorphous phase and crystalline lamellae. From that point of view, semi-crystalline thermoplastics contain several tens percents of nanofillers (their crystalline lamellae). Thus, the further addition of a few percents of inorganic lamellar fillers will not increase drastically the macroscopic properties of semicrystalline polymers, unless a synergy is created between the inorganic lamellar fillers and the crystalline lamellae of the polymer. This seems to occur in polyamide-6/montmorillonite nanocomposites, because montmorillonite acts as a nucleating agent by promoting the crystallization of polyamide- 6 into the $\gamma$ phase [11]. A synergy between the inorganic fillers and the crystalline lamellae of the polymer is however not sufficient to obtain improved macroscopic properties, since a good dispersion of the filler has to be ensured, and probably also given orientations of the fillers and of the lamellae.

In order to understand the macroscopic properties of polymers filled with inorganic lamellar fillers, it is thus unavoidable to precisely characterize their structures. In the present paper, we propose a procedure for determining the microstructure of semi-crystalline polymers filled with lamellar materials, in the most quantitative way as possible. The parameters on which we will focus are the dispersion state of the filler particles, the orientation of the filler particles 
and of the polymer crystalline lamellae and finally the relationships between the filler particles and the polymer crystalline lamellae (characterization of the interfacial adhesion strength).

\section{Experimental conditions}

The matrices used in this study are a polyamide- 6 (Ultramid ${ }^{\circledR}$ from BASF, $\mathrm{M}_{\mathrm{w}}=6.5610^{4}$ g.mol ${ }^{-1}$ ) or high-density polyethylene (Eraclène ML 74 from Polimeri Europa, $\mathrm{M}_{\mathrm{w}}=1.2010^{5}$ g.mol $\left.{ }^{-1}\right)$. In order to ensure a better interaction between the clay and the polyethylene, maleic acid-grafted polyethylene (PE-g-AM) was used (456-624 from Sigma-Aldrich, $\mathrm{M}_{\mathrm{w}}=1.0410^{4}$ g.mol $\left.{ }^{-1}\right)$. We used two different montmorillonites supplied by Süd Chemie. The Nanofil 804 clay was introduced in the polyamide matrix whereas the Nanofil 15 clay was introduced in the binary polyethylene blends. Both montmorillonites were cationic exchanged by quaterny amonium ions, i.e. dihydroxy-methyl-tallow for Nanofil 804 and dimethyl-ditallow alkyl ammonium for Nanofil 15, in similar ratios (36\% and 30\% for Nanofil 804 and Nanofil 15, respectively), but show different interlayer distances, $28 \AA$ for Nanofil 804 and $18 \AA$ for Nanofil 15.

Two compounds, 95 wt.\% PA-6 + 5 wt.\% Nanofil 804 (further called PA/clay) and 75 wt.\% PE + 20 wt. \% PE-g-AM + 5 wt.\% Nanofil 15 (further called PE/clay) were elaborated by melt intercalation on a pilot twin-screw extruder, with a diameter $\mathrm{D}=25 \mathrm{~mm}$, a length equivalent to $36^{*} \mathrm{D}$ and a rate of $3 \mathrm{~kg} / \mathrm{h}$. Temperature was ranking from $130^{\circ} \mathrm{C}$ at feeder to $200^{\circ} \mathrm{C}$ at die for the polyethylene compounds and from 170 to $260{ }^{\circ} \mathrm{C}$ for the polyamide compounds, the screw speed is set between 70 and $100 \mathrm{rpm}$ in order to keep the machine torque constant at $95 \%$ of the maximum extruder torque. The compounds were then blown extruded on a Colin Teach Line into films of thickness $100 \mu \mathrm{m}$ for the polyethylene and $80 \mu \mathrm{m}$ for the polyamide. Directions were defined on the blown extruded films as machine direction Md (which is the 
extrusion direction), transverse direction $\mathrm{Td}$ (blowing direction) and normal direction $\mathrm{Nd}$ (direction normal to the plane of the film).

Optical microscopy observations were carried out on a Zeiss microscope at low magnification (x30). For Transmission Electron Microscopy (TEM) observations, the films were embedded in an epoxy (Epofix) resin. As the montmorillonite particles tend to lie parallel to the film surface, the samples were cut (with an ultramicrotome Reichert S) in order to observe the particles on their edges. To obtain sections thin enough and to avoid distortions such as thickness ripples, the surface of the pyramid was roughly set to $0.1 * 0.1 \mathrm{~mm}^{-1}$ and a $35^{\circ}$ diamond knife was used. For PE/clay, the temperature was set to $-130^{\circ} \mathrm{C}$, the knife speed to $1 \mathrm{~mm} / \mathrm{s}$ and the thickness to $30 \mathrm{~nm}$. For PA/clay, ultramicrotomy was performed at room temperature under the same conditions. Finally, the sections were mounted on a 400 mesh copper grid. The TEM bright field observations were performed on a Jeol-200CX microscope operating at $200 \mathrm{kV}$. Wide-Angle-X-ray Scattering (WAXS) and Small Angle X-Ray Scattering (SAXS) were carried out at room temperature in transmission mode using a Princeton SCX2D CCD camera. The X-ray beam was collimated with a point-focusing Göbel mirror from Xenocs that ensured both monochromatized $\mathrm{Cu}-\mathrm{K}_{\alpha}$ radiation $(\lambda=1.54 \AA$ ) and a parallel point-focusing. The sample consisted in stacks of 15 to 20 films. In the WAXS configuration, two sample-to-detector distances were used and allowed to explore a wide range of scattering vectors, from $\mathrm{q}=0.6$ to $6 \mathrm{~nm}^{-1}$. SAXS was used to characterized the diffusion of the clay tactoids platelets and to determine a thickness distribution. The sampleto-detector distance was set to $690 \mathrm{~mm}$ and thus the scattering vector was varied between 0.1 and $1.1 \mathrm{~nm}^{-1}$. Corrected $2 \mathrm{D}$ scattering pattern were obtained taking into account the transmission coefficient, and the background diffusion with and without the X-Ray beam. 


\section{Results and discussion}

\section{Clay dispersion state}

In order to describe the state of exfoliation and intercalation, two techniques are the most common and easy of use for structure characterization. The evolution of the interlayer distance can be followed by Wide-Angle X-Ray Scattering (WAXS) but in some cases (for example a random orientation of the layers, a large amount of clay, an inhomogeneous distribution of surfactant in the interlayer space, or a distribution of interlayer distance), it can lead to a false interpretation of the microstructure. For these reasons, many authors $[12,13$, 14] suggest to compare the results obtained by WAXS with direct observations of the clay layers by Transmission Electron Microscopy (TEM). A single TEM micrograph is usually given in the literature and on the basis of that micrograph, the structure is called either exfoliated or intercalated. The main problem of TEM is that the volume probed is very small and a single TEM micrograph may not be representative of the nanocomposite in its whole. In practice, the organization of the clay layers in the matrix is more complicated : the concept of order/disorder has to be introduced and exfoliated filler platelets, intercalated tactoids and immiscible phases may co-exist.

Several studies used TEM image analysis to characterize the dispersion state of the particles in the nanocomposites $[15,16,17,18]$. They generally calculated the average thickness and length of the tactoids, the interparticular distance, the average number of platelets per tactoid and they evaluate the quantity of distinguishable clay entities in the matrix. All these last pieces of information are of real importance as they influence the final properties of the nanocomposite. However, the proportion of micron-size agglomerates was not taken into account in the literature. Therefore, we developed an image analysis procedure based on both Optical Microscopy (OM) and TEM for evaluating the dispersion state of montmorillonite platelets in a polymer matrix. The detailed procedure is described elsewhere [19]. Several 
classes of clay particles were arbitrarily defined according to their thickness, ranging from a single exfoliated platelet to micron size agglomerates. Their thickness e and length $\mathrm{L}$ were measured, as well as the distances $\varepsilon / /$ and $\varepsilon_{\perp}$ between two adjacent clay particles in the directions parallel and perpendicular to that of their mean orientation, respectively (see Figure 1). OM/TEM image analysis performed on several polymer/montmorillonite nanocomposites revealed that neither of them could be classified as pure exfoliated or pure intercalated systems; there was instead co-existence of exfoliated sheets, tactoids and micron-size agglomerates. Moreover, the proportion of micron-size agglomerates could often not be neglected, which shows the need to characterize the dispersion of the montmorillonite platelets from the nanometer scale to the micron scale.

The OM/TEM image analysis is used to characterize the morphology of both PA/clay and PE/clay nanocomposites. The results are displayed in Table 1. The clay is relatively well dispersed in the PA/clay nanocomposite, since the proportion of micron size agglomerates $\mu_{\text {agglo }}$ represents only $0.9 \%$ of the clay total amount. Moreover, the average thickness $(<\mathrm{e}\rangle=$ $5.9 \mathrm{~nm}$ ), as well as the distribution of the clay particle thicknesses (see Figure 4) indicate that most of the clay tactoids composed of 2 or 3 platelets. On the contrary, the PE/clay nanocomposite contains a large amount of micron-size agglomerates $\left(\mu_{\mathrm{agglo}}=66 \%\right.$ of the clay total amount). As a consequence, the mean distances $\left\langle\varepsilon_{\varepsilon} /\right\rangle$ and $\left\langle\varepsilon_{\perp}\right\rangle$ and the particle density per $\mathrm{nm}^{2}$ are far higher than in the case of the PA/clay nanocomposite (450 and $280 \mathrm{~nm}$ compared to 100 and $63 \mathrm{~nm}$, respectively). The bad dispersion state of the clay in PE can be attributed to the difficulty to disperse a hydrophilic clay in a hydrophobic polymer, despite a hydrophobic surfactant used to functionnalize the clay.

Interestingly for both PA/clay and PE/clay nanocomposites, we observed very low average aspect ratios $(\langle\mathrm{AR}\rangle=13$ and 7 , respectively). A low average aspect ratio was expected in the case of the PE/clay nanocomposite since most of the montmorillonite particles are micron- 
size agglomerates. On the contrary, a high average aspect ratio, close to that of an exfoliated platelet (expected AR of several hundreds), was expected for the PA/clay nanocomposite, which mostly contains tactoids of 2 to 3 platelets. The difference between the observed and the theoretical aspect ratios was studied elsewhere $[32,20]$ and is probably due to the projection effect in the TEM.

The main limitation of TEM is that the volume probed is very small. It is thus often argued that the results obtained by TEM are not representative of the materials in its whole. WAXS and SAXS can also give pieces of information regarding the platelets. These results can be considered as representative of the whole materials since the analyzed volume is about $1 \mathrm{~mm}^{3}$ with standard equipments. As far as SAXS is concerned, two entities can give rise to diffusion: the montmorillonite platelets and the polymer crystalline lamellae. The diffusion by the inorganic clay platelets is far more intense that the diffusion by the crystalline lamellae. If both signals are superimposed, SAXS may not be a convenient technique to characterize polymer/platelets nanocomposites. Moreover, due to experimental uncertainties at very small angles, only the smallest entities can be observed by SAXS under our conditions. On the contrary by WAXS, there is no limitation regarding the size of the diffracting entities, except that exfoliated platelets remain invisible since they can not diffract. Although the thickness of the diffusing/diffracting entities can theoretically be determined by WAXS, the full width at half maximum of a diffraction peak on a WAXS diffractogram depends on both the thickness of the diffracting entity (then on the number of montmorillonite platelets per tactoid) and its perfection (evenness of the stacking).

We compare the results obtained on PA/clay and PE/clay films, with both the OM/TEM image analysis and SAXS. In these films, in which the clay platelets are highly oriented parallel to the machine direction Md (see below), the 2-dimensional diffusion patterns are 
found to be highly dependent on the relative orientation of the incident X-Ray beam, the sample and the detector, see Figure 2. The pattern which gives the most interesting pieces of information is that obtained when analyzing along direction Td. Figure 3a displays that pattern obtained on the PE/clay film. The diffusion from the platelets and from the crystalline lamellae are perpendicular to each other. On the basis of a long period equal to $20 \mathrm{~nm}$ in polyethylene and the thickness of a crystalline lamella equal to $15 \mathrm{~nm}$ (common values of high density polyethylene), the diffusion due to the crystalline lamellae is almost concentrated into one spot (equatorial direction). On the contrary, the montmorillonite platelets are not well exfoliated and the size of the tactoids can vary from $1 \mathrm{~nm}$ (exfoliated platelets) to the micron range (agglomerates). This leads to a much more extended diffusion signal (polar direction). Note that the signal due to the montmorillonite platelets is also far more intense than the signal due to the crystalline lamellae, as expected. According to the results obtained on these films by the OM/TEM image analysis, the diffusion along the polar direction is due to the diffusion of several sizes of tactoids. The signal could be fitted by the weighted sum of the contributions arising from the 5 entities defined for the OM/TEM image analysis [20]. The proportion of each entity could then be determined and compared to that obtained by OM/TEM image analysis, see Figure 4a for PA/clay and Figure $4 \mathrm{~b}$ for PE/clay. Note that due to experimental uncertainties at the very small angles, tactoids bigger than $50 \mathrm{~nm}$ could not be observed by SAXS. Nevertheless, a good agreement could be found between SAXS and the OM/TEM image analysis. This shows that the OM/TEM image analysis procedure can efficiently describe the clay dispersion state. This also shows that the distribution of the tactoids thinner than $50 \mathrm{~nm}$ can be obtained by SAXS.

\section{Clay and polymer crystalline lamellae respective orientation}


The orientation of the entities can be determined by both SAXS and WAXS : SAXS will directly give the orientation of entities smaller than about $50 \mathrm{~nm}$. By WAXS, the signal collected is dominated by the bigger entities. When analyzing bulk materials or films, it is necessary to compare the WAXS patterns obtained along the 3 possible directions. A similar procedure can be applied to obtain the thickness of the crystalline lamellae and their orientation.

From the SAXS pattern collected when analyzing along direction $\mathrm{Md}$, the respective orientation of the montmorillonite particles (exfoliated platelets and tactoids up to $50 \mathrm{~nm}$ thick) and the crystalline lamellae can be deduced. Obviously, the montmorillonite particles lie parallel to the extrusion direction and the crystalline lamellae are perpendicular to the montmorillonite particles, as represented in Figure 3b. In order to obtain a 3-dimensional view of the orientation of the clay particles and crystalline lamellae, the 2-dimensional SAXS patterns along the 3 directions have to be considered. Moreover, one of the ways to quantify their orientation is to draw a diagram called Wilchinsky diagram. The detailed procedure is described elsewhere by Bafna et al. [21 ]. In the blown-extruded films of PA/clay and $\mathrm{PE} /$ clay, the montmorillonite particles were always found to lie in the extrusion plane ((MdTd) plane). The orientation of the crystalline lamellae was found to be dependent on the extrusion-blowing experimental conditions. They were generally found to be perpendicular to the montmorillonite particles, as was previously shown in the literature [22, 23]. However, the were found to be either distributed orthotropically or completely oriented with their normal parallel to the machine direction Md.

\section{Matrix/clay interfacial adhesion strength}

Lastly, the macroscopic properties of the nanocomposites obviously depend on the interfacial adhesion strength between the filler and the matrix. The interface thus needs to be 
characterized in terms of interactions of polymer chains on the platelets. Yet, it is difficult to determine by TEM or by Differential Scanning Calorimetry (among other techniques) whether these interactions exist or not. We propose the use of Dynamic Mechanical Analysis (DMA) as an indirect technique to probe the filler/matrix interface. In the literature, DMA is generally used to check that inorganic platelets have a reinforcement effect [24, 25, 26, 27]. When the authors try to relate the mechanical properties and the microstructure of the nanocomposites, it is often stated that the reinforcement effect is probably due to the dispersion state and/or aspect ratio of the dispersed clay particles [28, 29, 30], but the dispersion state was not quantitatively measured. H. Miyagawa et al. could explain the reinforcement effect of the clay in epoxy by the influence of the aspect ratio of the dispersed clay particles (Tandon and Weng model) [31]. The Tandon and Weng model can also well account for the influence of the filler aspect ratio on the reinforcement of semi-crystalline matrices filled with clay but unfortunately, this can not explain the higher reinforcement effect sometimes observed above the glass transition temperature of the semi-crystalline matrix (see Figure 5a for example). The non consistency of the Tandon and Weng model, as well as other two phase models, is due to the fact that above its glass transition temperature, the crystalline lamellae and the amorphous phase of a semi-crystalline matrix have to be separately taken into account (the modulus of the crystalline lamellae remains equal to about $1 \mathrm{GPa}$ whereas the modulus of the amorphous phase drops to a few MPa). Yet, three phase models (clay, crystalline lamellae and amorphous phase) may not accurately account for the observed reinforcement effect, because the matrix-clay interfacial adhesion strength also plays a major role on the reinforcement effect. Thus, we propose the use of the DMA spectra to indirectly probe the matrix-clay interfacial adhesion strength.

Two examples of DMA spectra are presented in Figure 5. Figure 5a displays the DMA spectra of the PA/clay film and of its pure matrix. It has been shown previously that below the glass 
transition temperature, the increase of $G^{\prime}$ is only due to the presence of the rigid montmorillonite platelets in the matrix, and can be predicted by simple models $[2,31]$. Thus, the values of $\mathrm{G}^{\prime}$ were normalized to 1 at $225 \mathrm{~K}$. Above the glass transition temperature, the reinforcement cannot be predicted by these models. One possible explanation of the relatively high reinforcement observed above $\mathrm{Tg}$ is that a network is formed from the montmorillonite platelets and the polyamide crystalline lamellae, as observed in the literature on other systems $[22,23]$. This is assigned to a good interfacial adhesion stregth between the montmorillonite platelets and the crystalline lamellae, most probably due to the fact that the montmorillonite platelets promote the crystallization of polyamide- 6 in the $\gamma$ phase. On the contrary, Figure $5 \mathrm{~b}$ displays the DMA spectra of the PE/clay film and of its corresponding pure matrix. The values of G' were also normalized to 1 below the glass transition temperature (108 K). Above Tg, a slight reinforcement was observed, which is assigned to the formation of poor interactions between the montmorillonite platelets and the polyethylene crystalline lamellae.

\section{Discussion of an "ideal" microstructure for improved mechanical properties}

From the results obtained with the procedure detailed above, we may be able to propose the structure which would lead to the highest reinforcement below and above all above $\mathrm{Tg}$. Obviously the clay particles have to be well dispersed, since the presence of a single micronsize agglomerate would act as a crack initiator and lead to a brittle behavior of the nanocomposite. From that point of view, the complete exfoliation of the clay platelets may play a second order role. Indeed, M. van Es previously showed that complete exfoliation might not be necessary to improve the macroscopic properties of the nanocomposites [32].

The second key parameter is probably the formation of a three-dimensional network from clay particles and crystalline lamellae, with a good interfacial adhesion strength between each other (as qualitatively determined by DMA). Such a three-dimensional network was proposed 
earlier elsewhere [22] but it has to be noticed that the formation of such a network would be possible only if the mean distance between two clay particles and the typical length of a crystalline lamella are of the same order of magnitude. From that point of view, there would be a critical weight fraction of clay above which the reinforcement is only related to the introduction of rigid particles in a soft matrix. When assuming that the dispersion and exfoliation states of the clay in a polymer matrix does not drastically depend on the clay content, the existence of a critical weight fraction of clay seems to be revealed by some data in the literature [25]. The value of the critical weight fraction is thought to be dependent on the state of exfoliation and of the preferential orientation of the clay particles. Of course, it is also thought to depend on the orientation of the crystalline lamellae, which are a consequence of the process conditions.

\section{Conclusions}

In this paper, we proposed a procedure to characterize the microstructure of polymer/clay nanocomposites, in terms of:

- clay dispersion state : an image analysis procedure, based on Optical Microscopy and Transmission Electron Microscopy, was developed to quantitatively determine these microstructural parameters (from the nanometer to the micron scale). Small Angle XRay Scattering was also used and confirmed the results obtained by the image analysis procedure.

- clay and polymer crystalline lamellae relative orientation : they were deduced from 2dimensional SAXS patterns obtained in three different directions and quantitatively determined through the use of the Wilchinsky diagram. 
- polymer/clay interfacial adhesion strength : we propose an interpretation of the DMA spectra, according which the intensity of the interfacial adhesion strength directly influences the intensity of the reinforcement above the glass transition temperature.

Finally, the existence of an "ideal" microstructure of polymer/clay nanocomposites with improved mechanical properties is discussed. It is thought that the clay dispersion state and the formation of a 3-dimensional network with clay particles, polymer crystalline lamellae and a great interfacial adhesion strength between each others are the key parameters. Moreover, it is thought that the process conditions also play a major role since they determine the clay dispersion state and orientation as well as the orientation of the polymer crystalline lamellae. From that point of view, the complete exfoliation of the clay may not be necessary and the clay fraction at which the three-dimensional network is just formed should be the optimum clay loading.

\section{References}

1 T. Lan, P.D. Kaviran, T.M. Pinnavaia, Chem. Mater. 1995, 7, 2144-2150.

2 K. Masenelli-Varlot, E. Raynaud, G. Vigier, J. Varlet, J. Polym. Sci. B 40, 2001, 272-283.

3 Y. Kojima, A. Usuki, M. Kawasumi, A. Okada, Y. Fukushima, T. Kurauchi, O. Kamigaito, J. Mater. Res. 8, 1993, 1185-1189.

4 Y. Kojima, A. Usuki, M. Kawasumi, A. Okada, T. Kurauchi, O. Kamigaito, K. Kaji, J. Polym. Sci. B 32, 1994, 625-630.

5 Y. Kojima, A. Usuki, M. Kawasumi, A. Okada, T. Kurauchi, O. Kamigaito, J. Appl. Polym. Sci. 49, 1993, 1259-1264.

6 P.B. Messersmith, E.P. Giannelis, J. Polym. Sci. A 33, 1995, 1047-1057.

7 E. Reynaud, Ph-D thesis \#2000-ISAL0070 (2000), INSA de Lyon, France.

8 L. Liu, Q.I. Zongneng, Z. Xiaoguang, J. Appl. Polym. Sci. 71, 1999, 1113-1138. 
9 Z.M. Liang, J. Yin, H.J. Xu, Polymer 44, 2002, 1391-1399.

10 Y. Yang, Z.K. Zhu, Jie-Yin, X.Y. Wang, Z.E. Qi, Polymer 40 (1999), 4407-4414.

11 K. Varlot, E. Raynaud, G. Vigier, J. Varlet, J. Polym. Sci. B 39, 2001, 1360-70.

12 A.B. Morgan, J.W. Gilman, J. Appl. Polym. Sci. 87 (2003), 1329-1338.

13 D. Garcia-Lopez, O. Picazo, J.C. Merino, J.M. Pastor, European Polymer Journal 39, 2003, 945-950.

14 R. Wagener, T.J.G. Reisinger, Polymer 44, 2003, 7513-7518

15 P.H. Nam, P. Maiti, M. Okamoto, T. Kotaka, N. Hasegawa, A. Usuki, Polymer 42, 2001, 9633-9640.

16 A. Ranade, N.A. D'Souza, B. Gnade, Polymer 43, 2002, 3759-3766.

17 H.R. Dennis, D.L. Hunter, D. Chang, S. Kim, J.L. White, J.W. Cho, D.R. Paul, Polymer 42, 2001, 9513-9522.

18 D. Marchant, K. Jayaraman, Ind. Eng. Chem. Res.41, 2002, 6401-6408.

19 A. Vermogen, K. Masenelli-Varlot, R. Séguéla, J. Duchet, S. Boucard, P. Prele, Macromolecules, 38, 23 (2005), 9661-9669.

20 A. Vermogen, K. Masenelli-Varlot, G. Vigier, G. Thollet, J. Duchet-Rumeau, Journal of Nanoscience and Nanotechnology, to be published.

21 A. Bafna, G. Beaucage, F. Mirabella, S. Mehta, Polymer 44 (2003) 1103.

22 G.M. Kim, D.H. Lee, B. Hollmann, J. Kressler, G. Stöppelmann, Polymer 42 (2001), 1095.

23 P. Maiti, M. Okamoto, Macromolecular Materials and Engineering 288 (2003), 440.

24 K.P. Pramoda, A. Mohamed, I.Y. Phang, T. Liu, Polymer International 54 (2005), 226.

25 J.H. Lee, D. Jung, C.E. Hong, K.Y. Rhee, S.G. Advani, Composite Science and Technology 65 (2005), 1996-2002.

26 S. Hambir, N. Bulakh, P. Kodgire, R. Kalgaonkar, J.P. Jog, J. Polym. Sci. B, 39 (2001), 446. 
27 G. Zhang, Y. Li, D. Yan, Y. Xu, Polym. Engin. Sci. 43 (2003), 204.

28 S. Xie, S. Zhang, F. Wang, H. Liu, M. Yang, Polym. Engin. Sci. 45 (2005), 1247.

29 L. Priya, J.P. Jog, J. Polym. Sci. B, 41 (2003), 31.

30 D. Ratna, G.P. Simon, J. Polym. Mater. 19 (2002), 143.

31 H. Miyagawa, M.J. Ricg, L.T. Drzal, Polymer Composites 26 (2005), 42.

32 M. van Es, Ph-D thesis, „Polymer-Clay nanocomposites - the influence of particle dimensions", TU Delft, 2001. 


\section{Figure and Table captions}

Figure 1 :Measurements for the OM/TEM image analysis. L : curved length of a clay particle; e : thickness of a clay particle; $\varepsilon_{/ /}$and $\varepsilon_{\perp}$ : distances parallel and perpendicular between two adjacent clay particles, respectively.

Figure 2 :Respective orientations of the incident X-Ray beam, the sample and the 2D detector for SAXS characterizations. The SAXS patterns of the PE/clay nanocomposite reveal a great anisotropy of the microstructure.

Figure 3 : a) SAXS pattern of the PE/clay nanocomposite, collected along direction Td. b) orientation of the montmorillonite platelets and of the polyethylene crystalline lamellae, determined from the SAXS pattern.

Figure 4 : Quantification of the dispersion of montmorillonite in the PA/clay (a) and in the PE/clay (b) nanocomposites. A good agreement is found between SAXS (-- • --) and the OM/TEM image analysis (---).

Figure 5 : DMA spectra of a) PA and PA/clay and b) PE and PE/clay. The increase of G' above the glass transition temperature is attributed to the formation of a percolating network, which rigidity depends on the polymer-clay interfacial adhesion strength.

Table 1 : Parameters calculated with the OM/TEM image analysis for the PA/clay and the PE/clay nanocomposites. $\mu_{\text {agglo }}$ estimation of the amount of micron-size agglomerates; <e> weight average thickness of the tactoids; $<\mathrm{L}>$ Weight average length of the tactoids; $<A R>$ Weight average aspect ratio of the tactoids; $\left\langle\varepsilon_{/ /}\right\rangle$inter-particular distance in the mean tactoids orientation and $\left\langle\varepsilon_{\perp}\right\rangle$ inter-particular distance perpendicular to the mean orientation. 


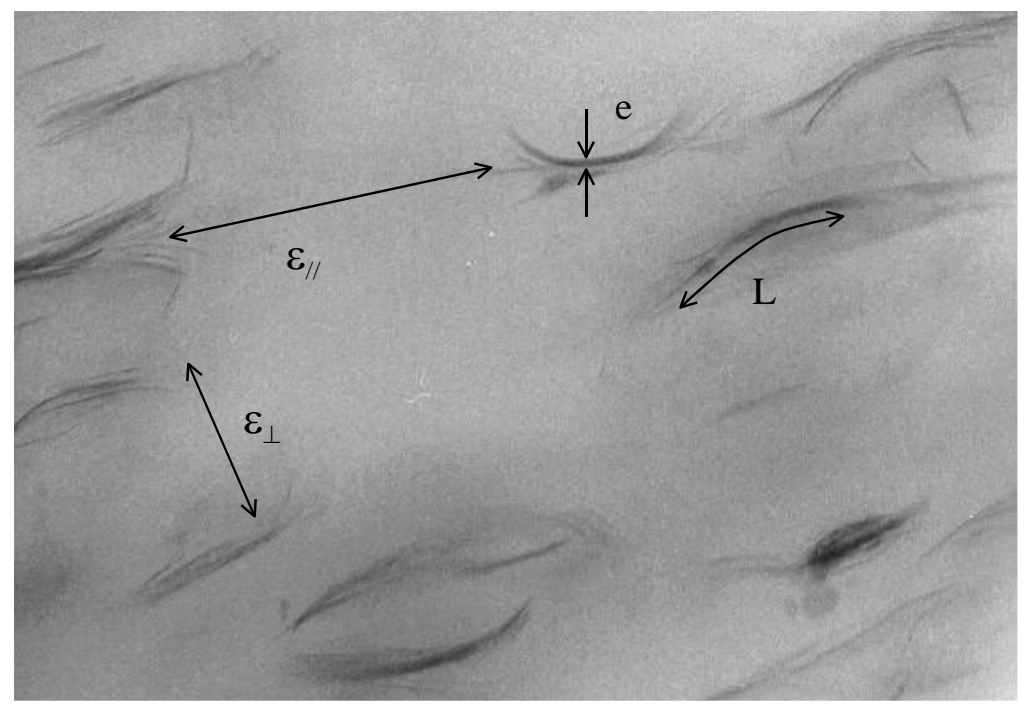

Figure 1 


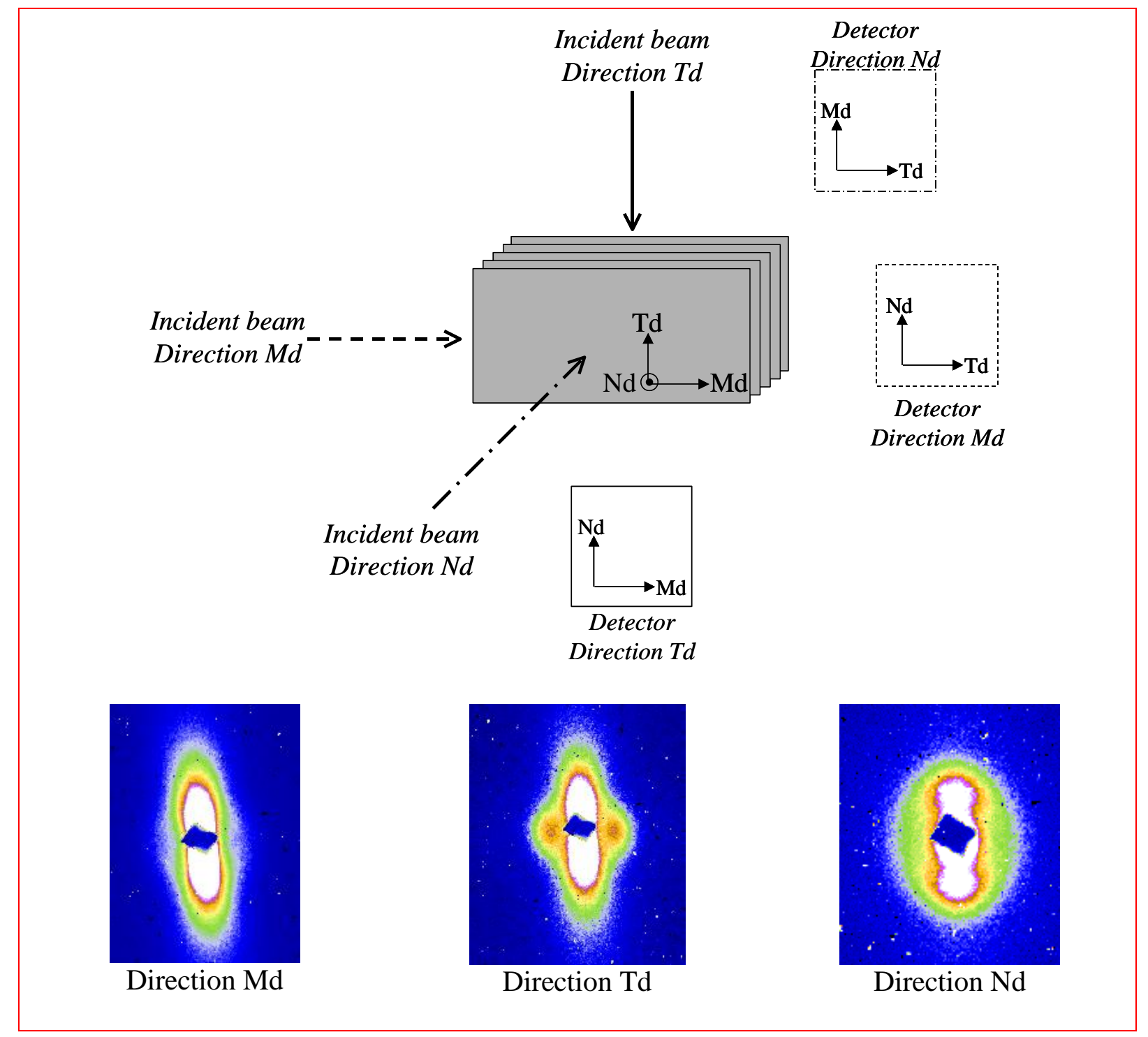

Figure 2 


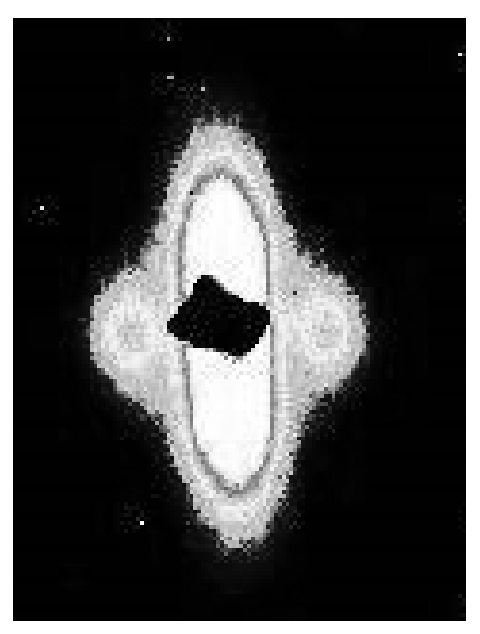

a)

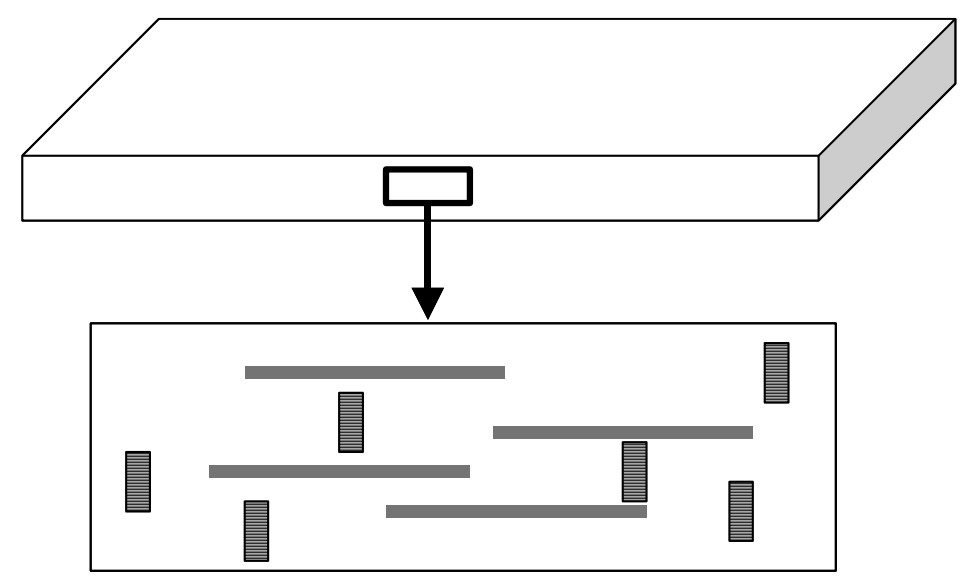

b)

Figure 3 


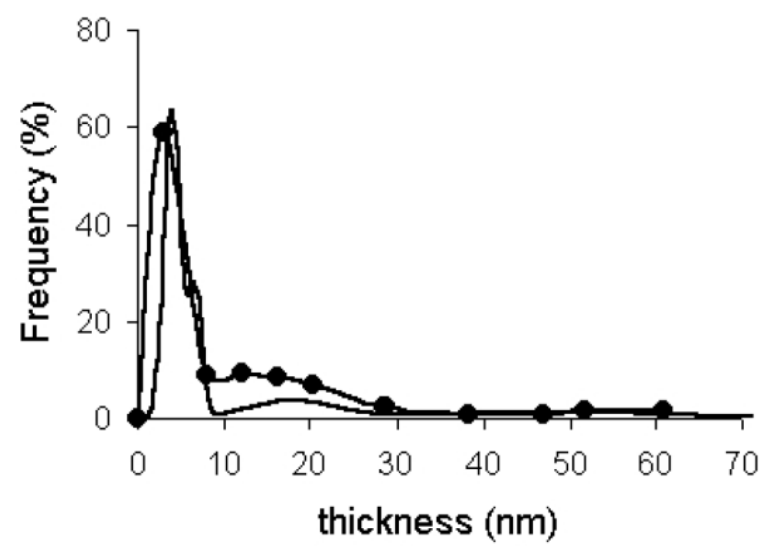

a)

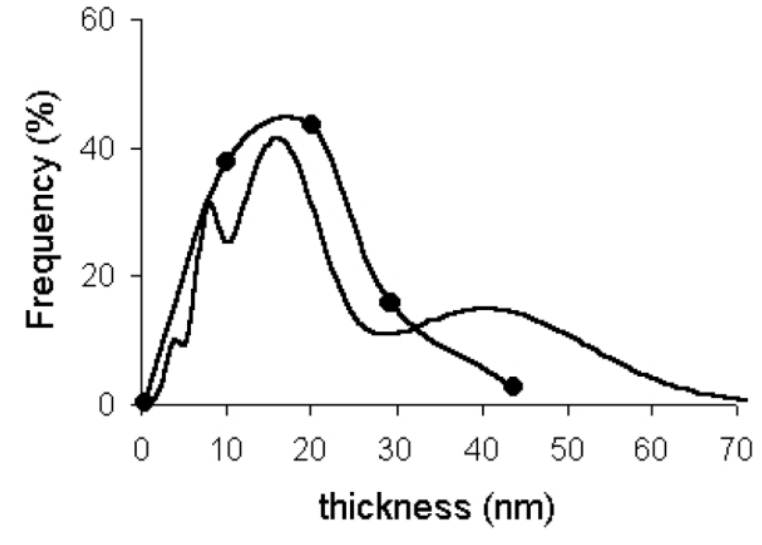

b)

Figure 4 


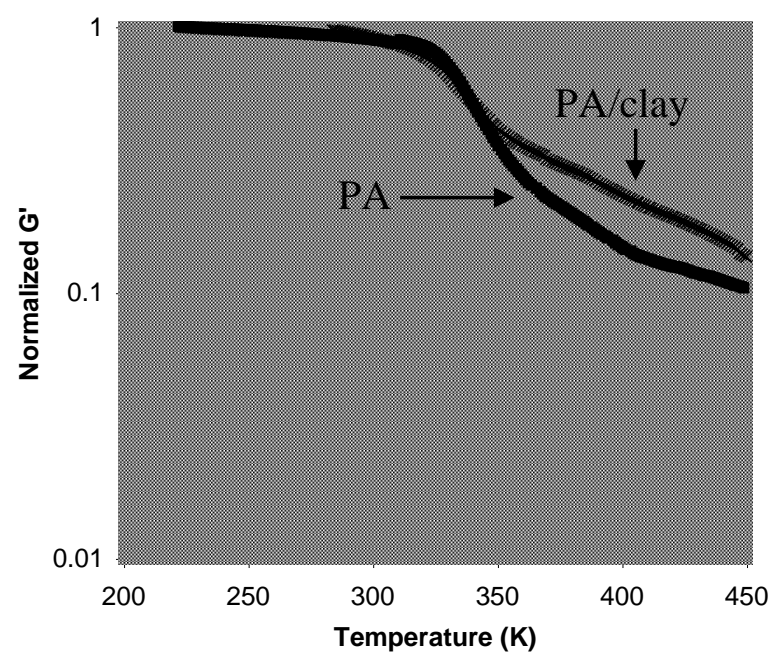

a)

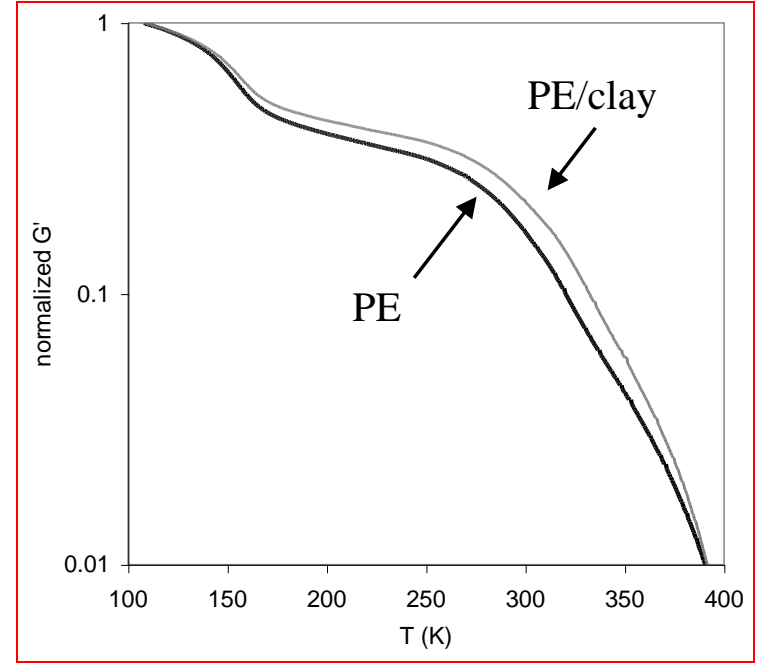

b)

Figure 5 


\begin{tabular}{|c|c|c|c|c|c|c|c|c|}
\hline Nanocomposite & $\begin{array}{c}\text { Number of } \\
\text { entities } \\
\text { analyzed }\end{array}$ & $\begin{array}{c}\mu_{\text {agglo }} \\
(\%)\end{array}$ & $\begin{array}{c}\langle\mathrm{e}> \\
(\mathrm{nm})\end{array}$ & $\begin{array}{c}\langle\mathrm{L}> \\
(\mathrm{nm})\end{array}$ & $\begin{array}{c}\langle\mathrm{AR}> \\
\left\langle\varepsilon_{/} />\right.\end{array}$ & $\begin{array}{c}<\varepsilon_{\perp}> \\
(\mathrm{nm})\end{array}$ & $\begin{array}{c}\text { Particle density } \\
\text { per } \mu \mathrm{m}^{2}\end{array}$ \\
\hline PA/clay & 274 & 0.9 & 5.9 & 66 & 13 & 100 & 63 & 200 \\
\hline PE/clay & 253 & 66 & 75 & 400 & 7 & 450 & 280 & 21 \\
\hline
\end{tabular}

Table 1 